\title{
Effect of Self-Regulated Learning for Improving Dietary Management and Quality of Life in Patients with Type-2 Diabetes Mellitus at Dr. Ramelan Naval Hospital, Surabaya, Indonesia
}

\author{
Yayuk Estuningsih', Thinni Nurul Rochmah2", Merryana Andriani ${ }^{3}$, Trias Mahmudiono ${ }^{3}$
}

\author{
${ }^{1}$ Nutrition Units, Dr. Ramelan Naval Hospital, Surabaya, Indonesia, ${ }^{2}$ Health Policy and Administration \\ Department, Faculty of Public Health, Universitas Airlangga, Surabaya, Indonesia, ${ }^{3}$ Nutrition Department, \\ Faculty of Public Health, Universitas Airlangga, Surabaya, Indonesia
}

\begin{abstract}
Self-regulated learning is a process of learning how to manage and regulate oneself to obtain skills and knowledge without depending on others. It is expected that diabetes patients can manage their diabetes by themselves. This study aimed to analyze the effect of self-regulated learning-based educational intervention on quality of life for patients with type-2 diabetes mellitus (DM) at Dr. Ramelan Naval Hospital, Surabaya. This was a quasi-experimental study in the form of pretest and posttest with a control group design. A total of 20 patients with DM were randomly divided into intervention and control groups to undergo a 4week intervention. The intervention group received dietary education with self-regulated learning, while the control group received standard education. The results revealed differences in variables such as dietary obedience, food intake at home, fasting blood sugar, diastolic blood pressure, and quality of life. The intervention group experienced a positive impact on the quality of life and resulted in better dietary obedience than that of the control group. In conclusion, the implementation of self-regulated learning-based dietary education can improve dietary obedience, knowledge, intention, family support, social support, physical activity, and quality of life for patients with type 2 diabetes.
\end{abstract}

Keywords: Diabetes mellitus, dietary obedience, quality of life, self-regulated learning

\section{Introduction}

Diabetes mellitus (DM) is a group of metabolic disorders characterized by hyperglycemia caused by the dysfunction of insulin secretion, insulin function, or both. ${ }^{1}$ The prevalence of DM has been increasing in both developed and developing countries over the past few decades. The International Diabetes Federation, ${ }^{2}$ has predicted a global increase in the number of people suffering from diabetes to a terrific 12 million by 2030 , up from 7 million in 2009. The number of people with diabetes in the 20-79-year age group in Indonesia has been estimated as ranking seventh among other countries. ${ }^{3}$ It is predicted that the prevalence of DM in Indonesia will double by 2030 compared to its prevalence in $2000 .{ }^{2}$ In Surabaya, the secondlargest city in Indonesia, the number of people with diabetes increased from 15,961 in 2010 to 21,268 in $2011 .{ }^{4} \mathrm{DM}$

How to Cite: Estuningsih Y, Rochmah TN, Andriani M, Mahmudiono T. The effect of self-regulated learning for improving dietary management and quality of life in patients with type-2 diabetes mellitus at Dr. Ramelan Naval Hospital, Surabaya, Indonesia. Kesmas: National Public Health Journal. 2019; 14 (2): 51-57. (doi:10.21109/kesmas.v14i2.2257) ranked third of the major diseases among hospitalized people who were diagnosed between 2011 and 2013 at Dr. Ramelan Naval Hospital. ${ }^{5}$

Among people with diabetes, the chronic hyperglycemic condition can lead to defects and dysfunction of several body organs in the long term, especially the eyes, liver, nerves, heart, and blood vessels. ${ }^{6}$ Therefore, any treatment for people with DM must be comprehensive to minimize negative effects. Treatment for DM must be comprised of namely four most important pillars of management: education, diet management, exercise, and medical treatment. ${ }^{4}$ Diet management will be most successful if diabetes patients achieve some level of self-regulated learning. One of the primary factors in diabetes patients' behavioral change lies in internal factors like self-motivation.

Self-regulated learning works on the concept of

\footnotetext{
Correspondence*: Thinni Nurul Rochmah, Health Policy and Administration Department, Faculty of Public Health, Universitas Airlangga, Surabaya 60115, Indonesia, E-mail: thinni_nurul@fkm.unair.ac.id, Phone: +62-812-3160-690 Received : May $22^{\text {nd }} 2018$

Revised : September $21^{\text {st }} 2018$

Accepted : June $14^{\text {th }} 2019$
} 
individuals learning to regulate their behavior. ${ }^{7}$ Selfregulated learning describes the process of how an individual activates cognition, behavior, and his or her feelings systematically and how they are oriented toward achieving the goal. ${ }^{7}$ A nutrition education intervention program provides self-regulated learning for people with diabetes in content areas; such as receiving relevant information, evaluating the information and comparing it with norms, triggering changes, searching for options, formulating a plan, implementing the plan, and assessing the effectiveness of the plan. The aim of this study was to analyze the effect of self-regulated learning-based education intervention in dietary management on quality of life for patients with type-2 DM who were hospitalized at Dr. Ramelan Naval Hospital.

\section{Method}

This was a quasi-experimental study with two groups of subjects and it was conducted in the forms of pretest and posttest with a control group design. The study population included all patients with diabetes who were hospitalized at Dr. Ramelan Naval Hospital, Surabaya, in April 2015. The participants were categorized into an intervention group and a control group. The inclusion criteria were patients diagnosed with type- $2 \mathrm{DM}$ with a minimum education level of junior high school, a minimum age of 20 years, who could read and perform activities independently, and who lived in Surabaya or Sidoarjo with their families. Patients with diabetes were those having who were excluded from the study complications of diabetic ulcers and gangrene; the patients with physical, mental, or cognitive disabilities or complications affecting food intake; and those not willing to participate.

The study sample was selected using the formula of hypothesis testing for two population means (two-sided test) ${ }^{8}$ Referring to the formula, the total sample required for each group was 10 respondents. The respondents were randomly selected based on the inclusion criteria during the survey administered at the hospitalization units. Patients became participants after they understood the study protocol and filled out the informed consent (Figure 1). Each group consisted of 10 patients with diabetes.

In this study, quality of life was assessed from two aspects, namely, subjective and objective quality of life. The subjective quality of life was measured using the World Health Organization Quality of Life - BREF questionnaire, which included physical and mental health dimensions, as well as psychology, social, and environmental questions. The questionnaire was previously validated by Agnihotri et al. ${ }^{9}$ Objective quality of life was measured based on blood sugar level, cholesterol level, systolic blood pressure, diastolic blood pressure, and body mass index (BMI) measurements. Another variable, dietary obedience, was assessed using a questionnaire consisting of the indicators of food waste at the hospital, food intake at the hospital, and food intake at home. To anticipate covariance variables such as the predisposing factor, the reinforcing factor, and the enabling factor, all the items were measured using the questionnaire. It consisted of nine questions addressing knowledge, belief, value, behavior, intention, family support, social support, pharmacology management, and physical activity management. All the question items in the questionnaire were validated $(r>$ 0.361 ) and had good reliability (Cronbach's alpha $\geq$ $0.6)$.

The respondents were then grouped based on nutrition education to compare its effect on each group. In both the control and intervention groups, participants received standard medical care such as measurements of the blood sugar level, cholesterol level, systolic blood pressure, diastolic blood pressure, and BMI. Besides, they were identified by their predisposing, reinforcing, and enabling factors through the questionnaire to analyze the influence of each factor on dietary obedience and quality of life. The intervention group was exposed to nutritional consultation followed by intensive monitoring using the self-regulated learning approach. The control group received only nutritional consultation provided at Dr. Ramelan Naval Hospital and/or at home without further monitoring using the self-regulated learning approach. Participants in the control group were asked to collect data, including their daily food intake at the hospital and $1 \times 24$-hour recall during their stay as an inpatient at the hospital. After the control group had left the hospital, they were asked for data by

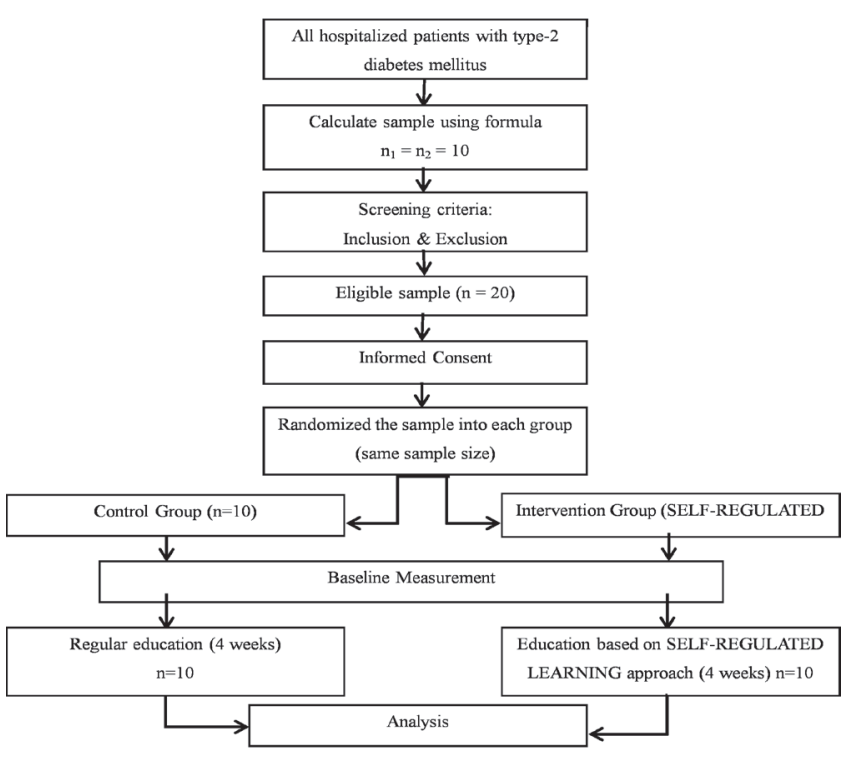

Figure 1. CONSORT Flow Diagram of the Study Sample and the Experimental Program 
carried out for a period of four weeks.

Participants in the intervention group were queried in the same manner as the control group regarding food intake at the hospital with $1 \times 24$-hour recall and were provided self-regulated learning-based nutrition education for four weeks following the baseline measurements. The nutrition education was imparted in a stepwise manner based on self-regulated learning every week. In the first week, the educational intervention consisted of information related to DM (definition, diagnosis, and treatment) and diabetic diets (aims, principles, eligibility, and physical exercise). Strategies to accelerate change were also explained in the educational intervention session. In the second week, the educational intervention taught the respondents in the intervention group about how to search for options and formulate a plan. Regarding the details of how to search for options, the educator asked respondents to describe the obstacles they had encountered during the diet program; thereafter, the educator compromised and negotiated with the respondents, so that they would understand the objective of the educational intervention. In formulating a plan, the educator helped the participants plan the diet, which consisted of time targets, activities, a peer group to follow and supportive people to be around during the diet. In the third week of intervention, the educator taught the aspects of implementing a plan and assessing the plan's effectiveness. In the fourth week, the education on assessing the plan's effectiveness was repeated. Once the respondents left the hospital, the educational intervention was continued at their homes.

An independent t-test was used to analyze the difference between the control and intervention groups, a paired t-test was used to compare data before and after the intervention in each group, and a linear regression test was used to analyze the correlation and determine the factors affecting the dependent variables. All statistical tests were two-sided, and a p-value $<0.05$ was considered statistically significant. Before the statistical analysis, the variables were examined for homogeneity using Levene's test. The result demonstrated that all the variables were homogeneous ( $p$-value $>0.05$ ) before the intervention, so that any difference in the posttest or after the intervention was attributable.

This study was carried out referring to the guidelines outlined in the Declaration of Helsinki. All the procedures involving human subjects and patients were approved by the Ethics Committee of the Faculty of Public Health, Universitas Airlangga, Indonesia. The ethical clearance No. 58-KEPK was issued on March 9, 2015. The approval for data collection was obtained from the Surabaya City Review Board and Dr. Ramelan Naval Hospital. Written informed consent was obtained from all participants before starting the study. The respon- dents were also informed that they could withdraw their participation in the study at any time without consequences.

\section{Results}

Most of the patients in each group were 40-59 years old (see Table 1). The control group had more female patients, while the intervention group had more males. Almost all the patients in the control group (80\%) had been diagnosed with type-2 DM for more than five years. The DM duration for the control group was classified into category of more than five years, while for intervention group the majority was classified into a category of less than three years. All the patients in both groups had low levels of knowledge related to dietary education before the intervention.

Before the intervention program, both the control and intervention groups were assessed for baseline measurements to analyze homogeneity by the required independent t-test. As shown in Table 2, all the variables were homogeneous ( $p$-value $>0.05$ ); therefore, this study can assure that any difference in the posttest analysis is attributable to the educational intervention. On the other hand, this result ensured that both the control and intervention groups were similar before undergoing the intervention and the program.

The intervention group's blood glucose, systolic blood pressure, and cholesterol levels showed a greater decrease than those in the control group. However, BMI showed only few changes; the change in BMI was negative because both the intervention and control groups had an increased BMI after the intervention program. Regarding diastolic blood pressure, only the intervention group exhibited a change, with a decrease from pretest to posttest.

Table 3 shows the results of the linear regression test to determine the factors affecting dietary obedience. Among the predisposing factors, knowledge and intention affected dietary obedience ( $\mathrm{p}$-value $<0.05)$. Among the reinforcing factors, family support influenced the dietary obedience of patients with type-2 DM. Among

Table 1. Characteristics of Respondents

\begin{tabular}{llrrrr}
\hline \multirow{2}{*}{ Category } & Characteristic & \multicolumn{2}{c}{ Control Group } & \multicolumn{2}{c}{ Intervention Group } \\
\cline { 3 - 6 } & & $\mathbf{n}$ & $\%$ & $\mathbf{n}$ & $\%$ \\
\hline \multirow{2}{*}{ Age } & 20-39 years & 0 & 0 & 1 & 5 \\
& 40-59 years & 6 & 60 & 11 & 55 \\
\multirow{2}{*}{ Sex } & $\geq 60$ years & 4 & 40 & 8 & 40 \\
\multirow{3}{*}{ Duration of } & Male & 3 & 30 & 8 & 80 \\
diabetes mellitus & Female & 7 & 70 & 2 & 20 \\
\multirow{2}{*}{ Knowledge level } & 3-5 years & 2 & 20 & 5 & 50 \\
& $>5$ years & 0 & 0 & 2 & 20 \\
& High & 8 & 80 & 3 & 30 \\
& Low & 0 & 0 & 0 & 0 \\
& & 10 & 100 & 10 & 100 \\
\hline \multirow{2}{*}{} & & & &
\end{tabular}


Table 2. Homogeneity Test of Variables before Intervention

\begin{tabular}{|c|c|c|c|c|c|}
\hline \multirow{2}{*}{ Factor } & \multicolumn{2}{|c|}{ Control Group } & \multicolumn{2}{|c|}{ Intervention Group } & \multirow{2}{*}{ p-Value } \\
\hline & Mean & SD & Mean & SD & \\
\hline Predisposing factors & 67.5 & 7.12 & 66 & 9.78 & 0.699 \\
\hline Knowledge & 9.1 & 2.51 & 7.8 & 2.74 & 0.284 \\
\hline Belief & 13.2 & 1.76 & 12.7 & 1.77 & 0.533 \\
\hline Value & 10.2 & 1.4 & 10.1 & 1.37 & 0.873 \\
\hline Attitude & 19.8 & 2.66 & 19.3 & 2.54 & 0.672 \\
\hline Intention & 15.2 & 3.04 & 16.1 & 3.5 & 0.546 \\
\hline Reinforcing factors & 17.8 & 3.9 & 15.7 & 4.0 & 0.251 \\
\hline Family support & 10.1 & 2.2 & 8.9 & 1.73 & 0.196 \\
\hline Social support & 7.7 & 2.4 & 7.6 & 2.36 & 0.926 \\
\hline Enabling factors & 18.6 & 2.32 & 18.6 & 3.17 & 1.000 \\
\hline Pharmacology management & 11.1 & 1.1 & 10.3 & 1.4 & 0.176 \\
\hline Physical activity management & 8.1 & 2.02 & 6.6 & 2.27 & 0.136 \\
\hline Dietary obedience & 976.88 & 54.56 & 906.54 & 141.65 & 0.160 \\
\hline Food waste at hospital & 602.8 & 335.71 & 566.27 & 275.8 & 0.793 \\
\hline Food intake at hospital & 976.88 & 54.55 & 906.54 & 141.65 & 0.160 \\
\hline Quality of life & 21.1 & 2.60 & 21.6 & 1.43 & 0.601 \\
\hline Subjective quality of life & 111.9 & 11.08 & 108 & 15.99 & 0.324 \\
\hline Objective quality of life & 12.4 & 2.27 & 13.2 & 1.03 & 0.758 \\
\hline Blood glucose level (mg/dL) & 268.4 & 69.18 & 258.9 & 66.62 & 0.758 \\
\hline Body mass index $\left(\mathrm{kg} / \mathrm{m}^{2}\right)$ & 21.57 & 3.73 & 24.27 & 4.47 & 0.160 \\
\hline Systolic blood pressure (mmHg) & 141 & 8.76 & 141 & 8.76 & 1.000 \\
\hline Diastolic blood pressure $(\mathrm{mmHg})$ & 93 & 6.75 & 95 & 5.27 & 0.470 \\
\hline Cholesterol level $(\mathrm{mg} / \mathrm{dL})$ & 325.3 & 52.65 & 323.3 & 33.79 & 0.917 \\
\hline
\end{tabular}

Table 3. Effect of Predisposing, Reinforcing, and Enabling Factors on the Dietary Obedience of Patients with Diabetes in Both the Intervention and Control Groups at Dr. Ramelan Naval Hospital in 2015

\begin{tabular}{lcc}
\hline & \multicolumn{2}{c}{ Dietary Obedience } \\
\cline { 2 - 3 } Variable & $\boldsymbol{\beta}$ & p-Value \\
\hline Predisposing factors & 0.522 & $0.000^{*}$ \\
Knowledge & 0.510 & $0.015^{*}$ \\
Intention & 0.453 & $0.001^{*}$ \\
Value & 0.253 & 0.108 \\
Attitude & 0.092 & 0.658 \\
Belief & -0.051 & 0.681 \\
Reinforcing factors & 0.318 & $0.013^{*}$ \\
Family support & 0.442 & $0.035^{*}$ \\
Social support & 0.382 & $0.064^{*}$ \\
Enabling factors & 0.342 & $0.009^{*}$ \\
Physical activity management & 0.607 & $0.006^{*}$ \\
Pharmacology management & 0.222 & 0.261 \\
\hline
\end{tabular}

Note: *Significant at $\alpha$ (alpha) $=5 \%$ based on multiple linear regression test.

intention affected dietary obedience ( $\mathrm{p}$-value $<0.05$ ). Among the reinforcing factors, family support influenced the dietary obedience of patients with type-2 DM. Among the enabling factors, physical activity management was found to influence the dietary obedience of patients with diabetes. Variables that did not influence dietary obedience included values, attitude, belief, social support, and pharmacology management ( $\mathrm{p}$-value > $0.05)$.

As shown in Table 4, several variables were different between the control and intervention groups after the intervention, such as dietary obedience, food intake at home, fasting blood glucose, diastolic blood pressure, subjective quality of life, objective quality of life, and quality of life ( $p$-value $<0.05$ ). Several variables showed no difference ( $p$-value $>0.05$ ), including food waste at the hospital, food intake at the hospital, BMI, systolic blood pressure, and cholesterol level.

Table 5 shows several changes in all variables after the program in both the control and intervention groups. Compared with the control group, several variables increased in the intervention group, including food waste (change $=-366.23)$, food intake $($ change $=879.25)$, dietary obedience (change $=1009.2$ ), quality of life (change $=3.4$ ), subjective quality of life (change $=18.6$ ), and objective quality of life (change $=2.4$ ).

\section{Discussion}

The results of this study agree with those reported by Dizaji et al., 10 showing an improvement in the know ledge score of patients with diabetes after the implementation of an educational intervention program. Therefore, it can be concluded that there was a positive impact on the knowledge of patients with diabetes. Behavioral change was one of the most difficult steps in the educational process, despite providing educational intervention to people for three months. ${ }^{10} \mathrm{~A}$ study by Skarbek, ${ }^{11}$ also mentioned that family support would help people with type-2 DM increase their self-efficacy in self-managing actions. A study by Mayberry and Osborn mentioned that instrumental support was the most common form of family support. ${ }^{12}$ Patients with diabetes got instrumental support from family members in areas such as diet, exercise, medication adherence, blood glucose monitoring, and managing doctors' 
Table 4. Differences in the Characteristics of Respondents after the Self-Regulated Learning Approach-Based Dietary Educational Intervention at Dr. Ramelan Naval Hospital in 2015

\begin{tabular}{|c|c|c|c|c|c|}
\hline \multirow{2}{*}{ Factor } & \multicolumn{2}{|c|}{ Control Group } & \multicolumn{2}{|c|}{ Intervention Group } & \multirow{2}{*}{ p-Value } \\
\hline & Mean & SD & Mean & SD & \\
\hline Food waste at the hospital & 263.8 & 110.05 & 200.04 & 50.25 & 0.120 \\
\hline Food intake at the hospital & 1551.22 & 337.58 & 1785.79 & 265.82 & 0.101 \\
\hline Food intake at home & 1559.04 & 339.71 & 2225.68 & 262.93 & $0.000 *$ \\
\hline Dietary obedience & 1555.13 & 238.65 & 2005.74 & 147.56 & $0.000 *$ \\
\hline Fasting glucose level (mg/dL) & 170.6 & 36.69 & 129.9 & 21.7 & $0.007 *$ \\
\hline Body mass index $\left(\mathrm{kg} / \mathrm{m}^{2}\right)$ & 21.74 & 3.27 & 24.66 & 5.01 & 0.140 \\
\hline Systolic blood pressure (mmHg) & 123 & 6.75 & 119 & 8.76 & 0.268 \\
\hline Diastolic blood pressure ( $\mathrm{mmHg}$ ) & 93 & 4.83 & 87 & 6.75 & $0.035 \%$ \\
\hline Cholesterol level (mg/dL) & 266.8 & 39.9 & 260.30 & 41.3 & 0.725 \\
\hline Subjective quality of life & 93.3 & 16.00 & 126.6 & 19.37 & $0.001 *$ \\
\hline Objective quality of life & 13.0 & 2.16 & 15.6 & 2.07 & $0.013^{*}$ \\
\hline Quality of life & 20.7 & 2.63 & 25.0 & 2.00 & $0.001 *$ \\
\hline
\end{tabular}

Note: *Significant at $\alpha$ (alpha) $=5 \%$ based on independent $\mathrm{t}$-test, SD $=$ Standar Deviation.

Table 5. Changes during the Study Period (Pretest and Posttest)

\begin{tabular}{|c|c|c|c|c|}
\hline \multirow{2}{*}{ Variable } & \multirow{2}{*}{ Group } & \multicolumn{2}{|c|}{ Mean Value } & \multirow{2}{*}{ Change } \\
\hline & & Pre & Post & \\
\hline \multirow[t]{2}{*}{ Food waste at hospital } & Control & 602.8 & 263.8 & -339 \\
\hline & Intervention & 566.27 & 200.04 & -366.23 \\
\hline \multirow[t]{2}{*}{ Food intake at hospital } & Control & 976.88 & 1551.22 & 574.34 \\
\hline & Intervention & 906.54 & 1785.79 & 879.25 \\
\hline \multirow[t]{2}{*}{ Dietary obedience } & Control & 976.88 & 1551.13 & 574.25 \\
\hline & Intervention & 906.54 & 2005.74 & 1099.2 \\
\hline \multirow[t]{2}{*}{ Subjective quality of life } & Control & 111.9 & 93.3 & -18.6 \\
\hline & Intervention & 108 & 126.6 & 18.6 \\
\hline \multirow[t]{2}{*}{ Objective quality of life } & Control & 12.4 & 13 & 0.6 \\
\hline & Intervention & 13.2 & 15.6 & 2.4 \\
\hline \multirow[t]{2}{*}{ Quality of life } & Control & 21.1 & 20.7 & -0.4 \\
\hline & Intervention & 21.6 & 25 & 3.4 \\
\hline \multirow[t]{2}{*}{ Blood glucose level } & Control & 268.4 & 170.6 & -97.8 \\
\hline & Intervention & 258.9 & 129.9 & -129 \\
\hline \multirow[t]{2}{*}{ Body mass index } & Control & 21.57 & 21.74 & 0.17 \\
\hline & Intervention & 24.27 & 24.66 & 0.39 \\
\hline \multirow[t]{2}{*}{ Systolic blood pressure } & Control & 141 & 123 & -18 \\
\hline & Intervention & 141 & 119 & -22 \\
\hline \multirow[t]{2}{*}{ Diastolic blood pressure } & Control & 93 & 93 & 0 \\
\hline & Intervention & 95 & 87 & -8 \\
\hline \multirow[t]{2}{*}{ Cholesterol level } & Control & 325.3 & 266.8 & -58.5 \\
\hline & Intervention & 323.2 & 260.3 & -63.2 \\
\hline
\end{tabular}

appointments. ${ }^{12}$ Furthermore, family support increased diabetes patients' capacity to choose appropriate foods according to their illness and condition. ${ }^{12}$

In managing their DM, patients must not only manage their diet appropriately but also their physical activity. Physical exercises should be performed continuously and regularly because the sensitivity of insulin receptors activated by the physical exercises does not last long. In addition, physical exercise has a weight loss benefit for obese and overweight people with diabetes. If managing diabetes mellitus through dietary regulation and physical activity does not succeed in maintaining normal blood glucose levels, then pharmacological therapy might be required. However, the most important intervention after pharmacological therapy is dietary management.
Self-efficacy plays a strong role in healthy eating and calories expended in physical activity, as does behaviorspecific support from family, friends, and community resources. ${ }^{13}$ As a predictor for a predisposing factor, intention evidently helps patients with diabetes achieve their goals and increase their self-efficacy. ${ }^{14}$ Furthermore, having achievable goals can help patients realize their intentions. ${ }^{14}$

In the present study, after the respondents received the four week educational intervention, they changed their behavior toward dietary obedience. A study by Dizaji et al., 10 demonstrated that the Precede Model provides an appropriate method of positive support in the educational intervention program through predisposing, reinforcing, and enabling factors after four weeks 
of intervention. This result was consistent with a study by Borhani et al.,15 that reported that the assessment of predisposing, reinforcing, and enabling factors in the educational process was highly effective toward behavioral change for self-treatment, especially for patients with diabetes mellitus.

Regarding the variable of dietary obedience, the present study used the indicators of food waste at the hospital, food intake at the hospital, and food intake at home, but only food intake at home had a difference. This might be because most of the respondents were unsatisfied with the taste of the meals served at the hospital. Moreover, the hospital did not accommodate their eating habits and preferred eating environments. Some obstacles were that the way the food was served was unattractive because of the limited utensils and the food tray. Patients' appetites also decreased because they were uncomfortable eating in the inpatient room. Regarding the food intake at home indicator, the intervention group showed an improvement in appetite due to the more comfortable psychological conditions and the fact that they completed their daily diet planning since receiving the nutrition education.

Diabetic education increased the positive health behaviors of patients with diabetes. These behaviors included healthy eating, physical exercise, and regular blood glucose control. These behavioral changes e vidently had a positive effect on controlling blood glucose level. ${ }^{16}$ People living with diabetes independently had higher self-confidence and self-management of diabetes than those who needed support. ${ }^{16}$ Behavioral changes reduces the risk of complications, which affects quality of life.

The significant improvement observed in the quality of life aspects in this study indicated that the selfregulated learning-based educational intervention had an impact on quality of life for people with diabetes. As argued by Waspadji, ${ }^{17}$ self-regulated learning-based educational intervention that provides knowledge and skills for people with diabetes is an attempt to create sustainability in behavioral change to improve an individual's ability to take care of their health independently, so that they can achieve a better of quality of life. Overall, this study is consistent with a study by Zareban et al., 18 which indicated that people with diabetes who received educational intervention would have better obedience behavior than those who did not receive education.

One impact of behavioral change was to control blood glucose levels, which became an indicator of quality of life in this study. In the control group, diastolic blood pressure was still indicated by hypertension, unlike the intervention group, which had a mean value in the category of normal diastolic blood pressure. The United
Kingdom Prospective Diabetes Study Group 38 reported a decline in the mean value of blood pressure compared to the no-strict diet group based on the effect of strict control of blood pressure for patients with diabetes. ${ }^{19}$

This study included only a small number of participants because of the difficulty and restriction of obtaining inclusion and exclusion criteria for the inpatient respondents. The representative distribution of population in this study cannot confirm the results of the statistical analysis since the sample size was not fully powered. The power test for sample size calculated using $\mathrm{R}$ with a minimal effect size by Cohen $\mathrm{d}=0.2$ gave a result of 0.07 or $7 \%$, which had to be reported for the accountability of this study. ${ }^{20}$

A few limitations of this study deserve consideration. First, this study was related to dietary management based on self-regulated learning and considered an alternative to nutrition education for patients with DM to improve their health status. Second, the change in food intake at home was not analyzed during the study period (Table 5) since the respondents were admitted as inpatients at the hospital for the first week of the program. Therefore, there was no change during the pretest and posttest in the variable of food intake at home. To the best of our knowledge, this study might fill the void of evidence related to diabetes intervention in an Indonesian setting, which is a rarity in peer-reviewed journals.

\section{Conclusion}

This study demonstrated that self-regulated learning is effective in increasing the quality of life and the dietary obedience of people with DM and in decreasing the blood glucose level, diastolic blood pressure, systolic blood pressure, and cholesterol level. Furthermore, selfregulated learning for patients with diabetes can improve knowledge and change intentions, improving the need for family and social support and the intention to be physically active.

\section{Acknowledgment}

We acknowledge the contributions of Hanin Dhany Robby in translating and copy editing the manuscript. We would like to thank Dr. Ramelan Naval Hospital of Surabaya for facilitating the study.

\section{References}

1. American Diabetes Association. Standards of medical care in Diabetes 2010. Journal of Diabetes Care. 2010; 33(1): 11-61.

2. International Diabetes Federation. Panduan global untuk Diabetes Tipe 2. Brussels: International Diabetes Federation; 2010.

3. International Diabetes Federation. Diabetes estimates across the globe [Internet]. 2017 [cited 2018 Mar 18]. Available from: http://www.diabetesatlas.org/across-the-globe.html

4. Perkumpulan Endokrinologi Indonesia. Konsensus pengelolaan dan 
pencegahan Diabetes Mellitus Tipe 2 di Indonesia. Jakarta: PB Perkeni; 2011.

5. Dr. Ramelan Naval Hospital. Medical record of Dr. Ramelan Naval Hospital Surabaya. Surabaya; 2014

6. Rondhianto. Self-management education dalam discharge planning terhadap self-efficacy dan self-care behaviour pasien Diabetes Mellitus Tipe

2. Universitas Airlangga; 2014.

7. Schunk DH, Zimmerman BJ. Motivation and self-regulated learning: theory, research, and applications. New York: Taylor \& Francis Group; 2012.

8. Levy PS, Lemeshow S. Sampling of populations: methods and application. 4th Edition. California: Wiley; 2013.

9. Agnihotri K, Awasthi S, Chandra H, Singh U, Thakur S. Validation of WHO QOL-BREF instrument in Indian adolescents. Indian J Pediatr. 2010; 77(4): 381-6.

10. Dizaji B, Taghdis M, Solhi M, Hoseini S, Mansou M, Shafieyan Z. Educational intervention based on precede model on self-care behaviours and control in patient with Type 2 Diabetes in 2012. J Diabetes Metab Disord. 2014; 13: 72.

11. Skarbek E. Psychosocial Predictors of self care behaviours in type 2 Diabetes Mellitus patient: analysis of social support, self-efficacy and depression. 2014; Available from: http://citeseerx.ist.psu.edu/ viewdoc/download?doi=10.1.1.18.7072-1.pdf

12. Mayberry LS, Osborn CY. Family support, medication adherence, and glycemic control among adults with type 2 diabetes. Diabetes Care. 2012; 35(6): 1239-45.
13. King DK, Glasgow RE, Toobert DJ, Strycker LA, Estabrooks PA, Osuna D, et al. Self-efficacy, problem solving, and social-environmental support are associated with diabetes self-management behaviors. Diabetes Care. 2010; 33(4): 751-3.

14. Didarloo A, Shojaeizadeh D, Gharaaghaji Asl R, Habibzadeh H, Niknami S, Pourali R. Prediction of self-management behavior among Iranian women with type 2 diabetes: application of the theory of reasoned action along with self-efficacy (ETRA). Iran Red Crescent Med J. 2012; 14(2): 86-95.

15. Borhani M, Rastgarimehr B, Shafi Z, Mansourian M. Effects of predisposing, reinforcing and enabling factors on self-care behaviors of the patients with diabetes mellitus in the Minoodasht City, Iran. J Diabetes Metab Disord. 2015; 14(1): 27.

16. Prihantini, Hariyati DS, Dewi NS. Model diabetic educator dalam peningkatan perilaku kesehatan. Jurnal Terpadu Ilmu Kesehatan. 2012; 1(Mei 2012): 94-100.

17. Waspadji S. Diabetes mellitus: mekanisme dasar dan pengelolaannya yang rasional: penatalaksanaan Diabetes Mellitus terpadu. Jakarta: Badan Penerbit FKUI; 2013.

18. Zareban I, Niknami S, Hidarnia A, Rakhshani F, Shamsi M, Karimy M. Effective intervention of self-care on glycaemia control in patients with type 2 diabetes. Iran Red Crescent Med J. 2014; 16(12).

19. Njoto EN. Target tekanan darah pada Diabetes Melitus. 2014; 41(11): 864-6.

20. Cohen J. Statistical power analysis for the behavioral sciences. 2nd Edition. New York; 2013. 